\title{
Results of endocapsular phacofracture debulking of hard cataracts
}

\author{
This article was published in the following Dove Press journal: \\ Clinical Ophthalmology \\ 10 July 2015 \\ Number of times this article has been viewed
}

James A Davison

Wolfe Eye Clinic, Marshalltown, IA, USA
Correspondence: James A Davison Wolfe Eye Clinic, 309 East Church Street, Marshalltown, IA 50I58, USA

Tel+I 64I 7546200

Email jdavison@wolfeclinic.com
Purpose/aim of the study: To present a phacoemulsification technique for hard cataracts and compare postoperative results using two different ultrasonic tip motions during quadrant removal.

Materials and methods: A phacoemulsification technique which employs in situ fracture and endocapsular debulking for hard cataracts is presented. The prospective study included 56 consecutive cases of hard cataract (LOCS III NC [Lens Opacification Classification System III, nuclear color], average 4.26), which were operated using the Infiniti machine and the Partial Kelman tip. Longitudinal tip movement was used for sculpting for all cases which were randomized to receive longitudinal or torsional/interjected longitudinal (Intelligent Phaco [IP]) strategies for quadrant removal. Measurements included cumulative dissipated energy (CDE), 3 months postoperative surgically induced astigmatism (SIA), and corneal endothelial cell density (ECD) losses. Results: No complications were recorded in any of the cases. Respective overall and longitudinal vs IP means were as follows: CDE, $51.6 \pm 15.6$ and $55.7 \pm 15.5$ vs $48.6 \pm 15.1$; SIA, $0.36 \pm 0.2 \mathrm{D}$ and $0.4 \pm 0.2 \mathrm{D}$ vs $0.3 \pm 0.2 \mathrm{D}$; and mean ECD loss, $4.1 \% \pm 10.8 \%$ and $5.9 \% \pm 13.4 \%$ vs $2.7 \% \pm 7.8 \%$. The differences between longitudinal and IP were not significant for any of the three categories.

Conclusion: The endocapsular phacofracture debulking technique is safe and effective for phacoemulsification of hard cataracts using longitudinal or torsional IP strategies for quadrant removal with the Infiniti machine and Partial Kelman tip.

Keywords: astigmatism, cataract, corneal endothelium, phacoemulsification, viscoelastic

\section{Introduction}

Two of the most commonly used strategies for phacoemulsification are in situ fracture and phaco chop. In situ fracture, ${ }^{1}$ ie, divide and conquer ${ }^{2}$ features low-vacuum sculpting of grooves in the nucleus, followed by fracturing the posterior nuclear plate, followed by the aspiration of usually four quadrants at higher vacuum and flow levels. In phaco chop, ${ }^{3}$ a varying number of sections are created by the chopping motion of a second instrument against the nucleus held by the phacoemulsification tip after it has burrowed into the central nucleus. Higher vacuum and flow are then used to aspirate the radially separated resultant segments.

More tip movement is required during sculpting with the in situ fracture technique, so machine-measured energy usage is always higher. However, the resultant quadrants are smaller, and space within the capsular bag will have been created during sculpting. This space can be utilized by allowing the quadrants to be pulled away from the posterior capsule and then aspirating them with high vacuum. Most of the technique can be accomplished within the capsular bag away from the corneal endothelium. Less tip movement is required with the phaco chop technique, so recorded energy expenditures are lower. But since there is no material removed during sculpting, the segments or quadrants may be larger. And since there is no created space available 
for centralization away from the posterior capsule, they (especially the initial ones) are usually pulled into the anterior chamber, away from the posterior capsule, but nearer to the corneal endothelium for safe removal. ${ }^{4}$

A mathematically estimated two-third nucleus volume reduction can be achieved by fracturing the nucleus into three pieces and then sculpting the nuclear walls. ${ }^{5}$ This relatively safe but energy-consuming nuclear volume reduction is particularly desirable during phacoemulsification of hard cataracts, where it is more difficult to protect both the posterior capsule and corneal endothelium.

This paper presents a hybrid variation ${ }^{6}$ of the in situ fracture technique, which incorporates further sculpting after posterior plate fracture, to achieve a debulking of four nuclear quadrants prior to their removal. It also presents a study of hard cataract case results using longitudinal vs IP (Intelligent Phaco) strategy for quadrant removal with the Alcon Infiniti machine and the Partial Kelman tip (Alcon Laboratories, Inc., Fort Worth, TX, USA).

\section{Materials and methods}

\section{Endocapsular phacofracture debulking technique}

Eyes were dilated with Cyclogyl 1\% and NeoSynephrine 2.5\%. Topical/intracameral anesthesia (preservative-free lidocaine $1 \%$ ) was used for all cases. Irrigation was provided via a balanced salt solution (BSS) (Alcon Laboratories, Inc.). The irrigation solution was supplemented with epinephrine and vancomycin (both from Hospira, Lake Forest, IL, USA) to achieve final concentrations of $.2 \mathrm{mg} / \mathrm{L}$ epinephrine and $60 \mathrm{mg} / \mathrm{L}$ vancomycin. All main incisions were $2.4 \mathrm{~mm}$, temporal, and limbal near-clear. DuoVisc (Alcon Laboratories, Inc.) viscoelastic was injected using a soft-shell technique. ${ }^{7}$ Approximately $0.1 \mathrm{~mL}$ of the dispersive viscoelastic (Viscoat, Alcon Laboratories, Inc.; sodium hyaluronate 3\% with chondroitin sulfate 4\%) was injected under the cornea's surface (approximately one-third fill of the anterior chamber). Then, approximately $0.2 \mathrm{~mL}$ of the cohesive viscoelastic (ProVisc, Alcon Laboratories, Inc.; 3\% sodium hyaluronate) was injected underneath the Viscoat to cover the anterior lens capsule and to push the Viscoat forward to coat the corneal endothelium and complete the filling of the anterior chamber. Capsulorhexes, with an intended $5.0 \mathrm{~mm}$ diameter, were performed using a bent needle cystotome, and hydrodissection was accomplished using a disposable Chang cannula (4036J, Oasis Medical Inc., San Dimas, CA, USA).

Alcon Infiniti phacoemulsification machines were used with the following features: $0.9 \mathrm{~mm}$ outside diameter, $12^{\circ}$ shaft angle (Partial Kelman), $45^{\circ}$ aperture, ABS Mini-flare tip; MicroSmooth Ultra Infusion Sleeve; and fluid management system (FMS) tubing and cassette. Continuous longitudinal tip motion was used for sculpting and volume reduction for both groups. For quadrant removal, the continuous longitudinal strategy was used for one group, and torsional with interjected vacuum demand triggered bursts of longitudinal (Intelligent Phaco, IP) strategy was used for the other (Table 1).

Deep grooves were sculpted in the nucleus at right angles to each other, then, the posterior nuclear plate was torn bimanually. The tip was then turned obliquely and used to debulk the nucleus by removing the remaining corners of the quadrants, leaving a thin peripheral nuclear shell. During quadrant removal, the first quadrant is mobilized with higher vacuum, rolled centrally, and then emulsified while being contained within the nuclear shell (Figure 1A-D). The remaining plates contain the central emulsification process and protect the posterior capsule, except for the last quadrant, which is held in a more anterior position with the tip aperture facing anterior (Figure 2A-D). In the hardest cases, reinjection of Viscoat was accomplished before emulsification of the last quadrant to physically insulate the corneal endothelium and posterior capsule. Lens cortex was removed with a disposable silicone tip attached to an irrigation/aspiration handpiece, and the posterior capsule vacuumed with it as well.

After anterior chamber reinflation with ProVisc, a single piece acrylic intraocular lens (IOL, Alcon Laboratories, Inc.) was injected into the capsular bag using a Monarch III injector (Alcon Laboratories, Inc.) loaded with Viscoat. Viscoelastic was removed from beneath the IOL optic and from the anterior chamber, as much as was safely possible in

Table I Ultrasonic energy and fluidic parameters for longitudinal and torsional (IP) quadrant removal

\begin{tabular}{lll}
\hline & Longitudinal & IP \\
\hline Scultp & & \\
Bottle & 78 & 78 \\
Phaco & 70 & 70 \\
Vacuum & 50 & 50 \\
AFR & 14 & 14 \\
Rise & 0 & 0 \\
Quadrant removal & & \\
Bottle & 85 & 85 \\
Phaco & $70^{\text {a }}$ & $100^{\text {b }}$ \\
Vacuum & 400 & 400 \\
AFR & 35 & 35 \\
Rise & -1 & -1 \\
\hline
\end{tabular}

Notes: a Continuous longitudinal; ${ }^{b}$ continuous IP with IP $90 \%$ vacuum trigger and I:I ratio and 0.7 seconds on time, with a minimum of 2 seconds continuous torsional prior to next activation.

Abbreviations: IP, Intelligent Phaco; AFR, aspiration flow rate. 
A

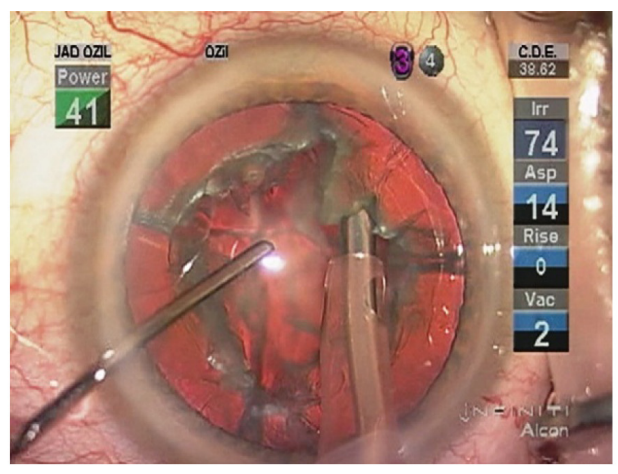

B

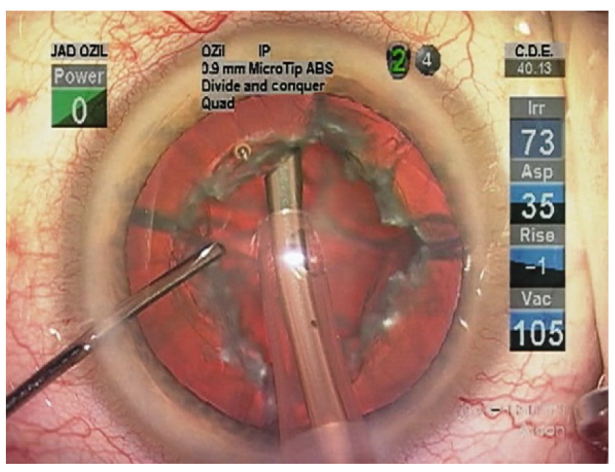

C

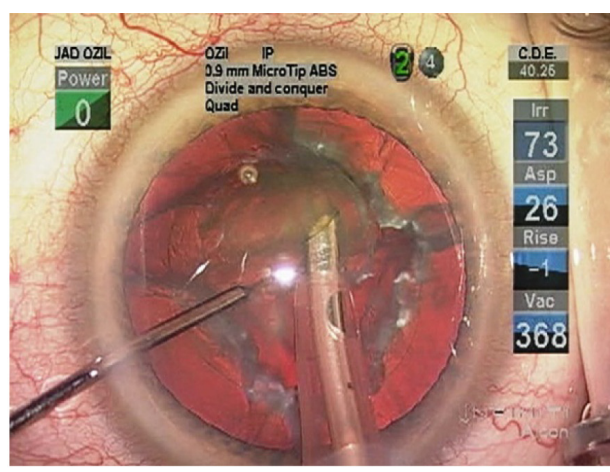

D

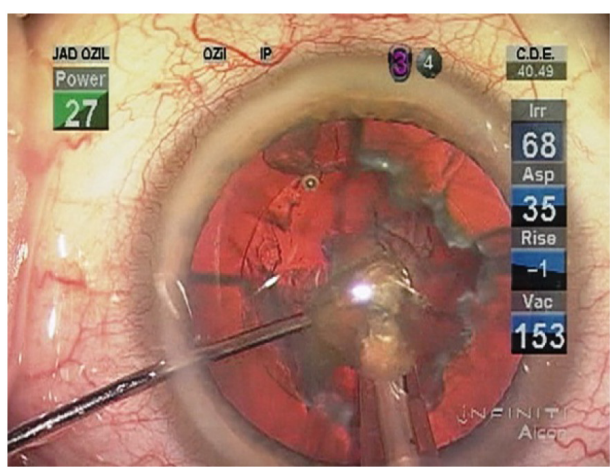

Figure I Aspiration of first quadrant.

Notes: (A) In foot position 3 (FP 3), the obliquely oriented tip is shaving the firm corner off the fourth quadrant in the final step of debulking the nucleus and creating a thin nuclear bowl. Low vacuum at $50 \mathrm{mmHg}$ and low flow at $14 \mathrm{cc} / \mathrm{min}$ prevent occlusion and inadvertent aspiration. (B) In FP 2, the obliquely oriented phaco tip aperture is poised in an access orientation to apply suction to the side of the first nuclear plate. Vacuum is starting to build and has reached $105 \mathrm{mmHg}$. (C) $\mathrm{A}$ tiny burst of low-power ultrasound has allowed the tip aperture to become occluded. Power has then been discontinued and vacuum has built to $368 \mathrm{mmHg}$ and is providing good suction adherence. This allows the first nuclear plate to be rolled into the bowl, which is now partial as it is comprised of three remaining plates. The longer $-\mathrm{I}$ rise time allows about I second to acquire and roll in the fragment before reaching maximum vacuum. (D) The nuclear fragment is held within the anterior central bowl by the nuclear plates, the phaco tip, and the cyclodialysis the custom 0.35 mm cyclodialysis spatula (SP765852, Baush + Lomb Stortz, Bridgewater, NJ, USA). Intermediate levels of vacuum, ultrasonic energy and flow simultaneously and in concert deform and emulsify the progressively smaller fragment while aspirating the emulsate.

Abbreviations: IP, Intelligent Phaco; CDE, cumulative dissipated energy; Irr, irrigation; Asp, aspiration; Vac, vacuum.

each case. Stromal hydration and ocular pressurization were achieved with BSS through a 30-gauge cannula, and all incisions were verified as self-sealing by incision compression with triangular synthetic sponges until normal intraocular pressure was achieved.

Values for cumulative dissipated energy (CDE) were recorded from the display panel of the phacoemulsification machine. The manufacturer defines longitudinal and torsional phacoemulsification CDE, respectively, as (phacoemulsification time $\times$ average phacoemulsification power at the proximal shaft) and (torsional time $\times 0.4 \times$ average torsional amplitude at the proximal shaft). ${ }^{8}$ This equation contains assumptions - including directional differences of stroke length vs rotational degree excursion, the maximum tip-end amplitude, and the frequency differences of the two modes ( $40 \mathrm{kHz}$ in longitudinal mode and $32 \mathrm{kHz}$ in torsional mode) - that resulted in the 0.4 multiplier (personal communication, Alcon Surgical, 2010). Intraoperative complications were recorded on the operation note at the time of surgery.

\section{Study of longitudinal vs IP in quadrant removal results}

The randomized prospective study presents a series of consecutive cases operated by the author in 2011. Randomization was accomplished using a table with even and odd numbers prior to the start of surgery. The study received Institutional Review Committee approval, and all patients signed appropriate informed consent. Inclusion criteria included diagnosis of cataract with Lens Opacification Classification System III, nuclear color (LOCS III NC) ${ }^{9}$ grade of 3.8-5.1. Exclusion criteria included corneal endothelial dystrophy, pseudoexfoliation, history of trauma or iritis, or previous eye surgery. Corneal endothelial cell photographs were taken and central corneal endothelial cell densities (ECDs) determined using a 100-cell standardized counting technique with a noncontact specular microscope camera (Konan SP9000, Hyogo, Japan). IOL calculations were accomplished using the IOLMaster, version 5 (Zeiss Humphrey, Carl Zeiss Meditec AG, Jena, Germany), for axial length and keratometry 
A

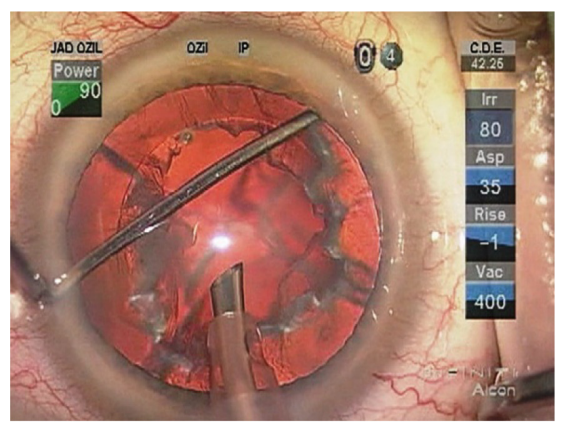

C

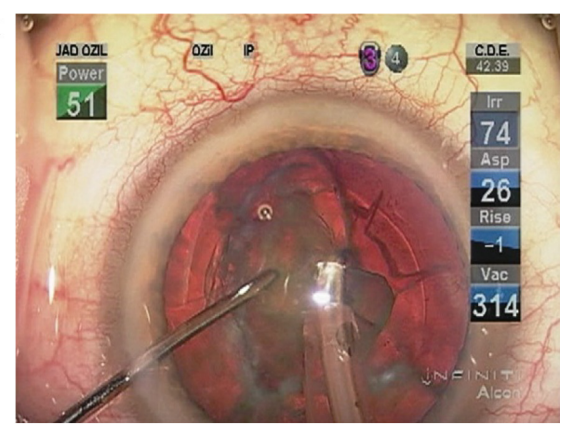

B

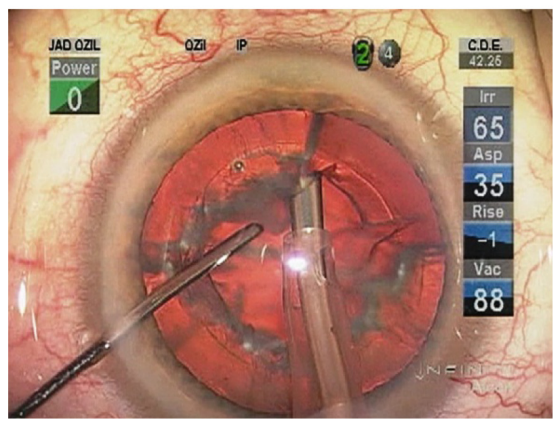

D

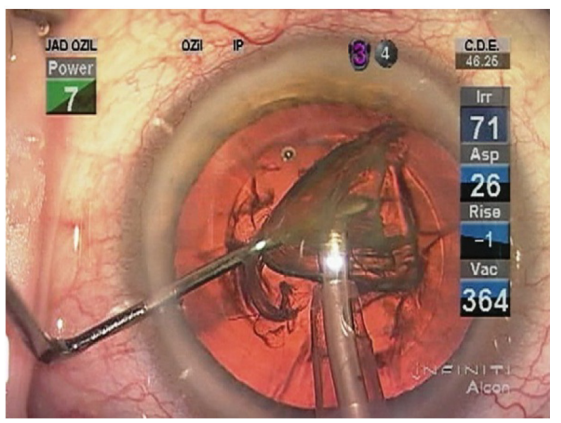

Figure 2 Emulsification and removal of subsequent nuclear plates.

Notes: (A) After the first quadrant has been aspirated, the cyclodialysis spatula is pushing on the peripheral edge of the fourth quadrant which easily rotates the second quadrant clockwise into its access position. (B) Flow of fluid has brought the fragment close to the tip aperture, and vacuum has reached $88 \mathrm{mmHg}$ as the obliquely oriented aperture is acquiring the edge of the second plate. (C) Roll in centralization is assisted by the cyclodialysis spatula. It also then contains the plate's position as it is being emulsified. The remaining two plates continue to form a partial bowl which creates a floor to insulate the posterior capsule from inadvertent aspiration. (D) The physical buffer of the nuclear bowl is gone as the fourth plate is being rolled into the iris plane for emulsification and removal. The cyclodialysis spatula helps manipulate and contain, but is mostly positioned under the phaco tip to protect the posterior capsule. Viscoelastic reinjection prior to this step pushes the posterior capsule back and insulates the corneal endothelium.

Abbreviations: IP, Intelligent Phaco; CDE, cumulative dissipated energy; Irr, irrigation; Asp, aspiration; Vac, vacuum.

determinations. ECD photographs and keratometry measurement by IOLMaster were accomplished 3 months after surgery for comparison.

Mean CDEs and preoperative vs postoperative measurements for mean ECD and automated keratometry changes were compared. A two-sample $t$-test, baseline-adjusted analysis of covariance (ANCOVA), $t$-test on changes from baseline, and $t$-test on percentage change from baseline were used to compare group ECD changes. Surgically induced astigmatism (SIA) was calculated using IOLMaster measurements in a proprietary formula derived by Warren Hill, MD (available at http://www.doctor-hill.com/physicians/ download.htm). The Wilcoxon rank sum test was applied to keratometric data. Statistical testing was accomplished by an independent statistician.

\section{Results}

There were no complications, including anterior radial capsular tears, noted in any of the cases of both groups.

A total of 56 cases had adequate pre- and postoperative endothelial cell photographs. Table 2 shows group similarities for age and LOCS III NC grading. Table 3 shows respective overall and longitudinal vs IP means for CDE, ECD loss, and SIA. The differences between longitudinal and IP were not significant for any of the three categories.

Machine-measured CDE correlated with LOCS III NC rating for both longitudinal and IP groups, respectively (coefficient: $0.64, P=0.0011$ and $0.77, P<0.0001$ ). There was no correlation of CDE to ECD loss for either longitudinal or IP groups (coefficient: $-0.31, P=0.1939$ and $-0.45, P=0.0673$ ).

\section{Discussion}

Modern techniques and high-performance machines have combined to produce innumerable effective strategies for phacoemulsification with somewhat different but comparatively similar results. Increased cutting efficiency with lower CDE measurement has been achieved with $22^{\circ}$ (Kelman) vs $12^{\circ}$ (Partial Kelman) distal shaft angles and $45^{\circ}$ vs $30^{\circ}$ tip aperture angles ${ }^{10,11}$ because of relatively greater tip movement at the aperture edge vs the shaft, where CDE is defined and measured. Aspiration efficiency has also been improved

Table 2 Preoperative and intraoperative case characteristics

\begin{tabular}{lllll}
\hline & $\mathbf{n}$ & Mean age & NC range & NC mean \\
\hline Longitudinal & 24 & 77.4 & $3.8-5.1$ & 4.2 \\
IP & 32 & 74.4 & $3.8-5.0$ & 4.3 \\
Overall & 56 & 75.7 & $3.8-5.1$ & 4.26 \\
\hline
\end{tabular}

Abbreviations: NC, LOCS III nuclear color; IP, Intelligent Phaco. 
Table 3 Postoperative results for ECD loss and SIA

\begin{tabular}{lllllll}
\hline & CDE* & Preoperative ECD & Postoperative ECD & Difference & $\%$ loss* & SIA (D)* \\
\hline Longitudinal & $55.7 \pm 15.5$ & 2,765 & 2,603 & 162 & $5.9 \pm 13.4$ & $0.30 \pm 0.2$ \\
IP & $48.6 \pm 15.1$ & 2,680 & 2,607 & 73 & $2.7 \pm 7.8$ & $0.40 \pm 0.2$ \\
Overall & $51.6 \pm 15.6$ & 2,716 & 2,606 & 110 & $4.1 \pm 10.8$ & $0.36 \pm 0.2$ \\
\hline
\end{tabular}

Note: $* P>0.05$.

Abbreviations: ECD, endothelial cell density; SIA, surgically induced astigmatism; CDE, cumulative dissipated energy; D, diopter; IP, Intelligent Phaco.

with torsional tip motion, especially with the Partial Kelman tip vs the straight tip, because of the reduction in repulsion and increased followability of nuclear material. ${ }^{12}$ However, similar corneal ECD losses have been reported with longitudinal motions of straight tips (7.1\%) and torsional tip motions of Kelman tips (7.2\%). ${ }^{13}$ Regardless of equipment or tip movement strategy, the task becomes increasingly difficult in harder cataracts. Higher ultrasonic energy expenditure is correlated with increasing LOCS III NC values ${ }^{14}$ and increased corneal ECD losses occur as cataract hardness increases. ${ }^{15}$ These hard cases require more exacting control and the exercise of substantial patience on the part of the surgeon in order to be accomplished effectively.

Phaco chop is popular because of its efficiency and has been shown to be effective in normal density cataracts. But in that strategy, larger nuclear fragments are drawn forward and emulsified in the anterior chamber which might possibly lead to increased corneal ECD losses. ${ }^{4}$ In one study using Viscoat and phaco chop on cataracts grade 1-4 with LOCS II, there was an association with moderate corneal ECD losses in both longitudinal (19.1\%) and torsional (12.5\%) tip movement strategies in very experienced hands, even while using Viscoat to protect the corneal endothelium. ${ }^{16}$ But in another with a subset of cases comprising harder cataracts (average LOCS III NO [nuclear opalescence] 4.0 ), phaco chop has more recently been shown to result in lower ECD losses (5.2\%) vs stop and chop (7.2\%) and divide and conquer $(9.1 \%) .{ }^{17}$ Viscoat was not used in cases of that study, and there were no differences in ECD losses between techniques in the removal of softer cataracts (NO 2 and NO 3).

The endocapsular phacofracture debulking technique described herein allows the surgeon to shave away hard nuclear material with low vacuum and low aspiration flow rate parameters, and then emulsify and aspirate relatively thin peripheral plates with higher vacuum and flow. The principles of the technique actually work with all grades of cataract. The softer the nucleus, the more the anterior material should be left to control the pace of acquisition, depth of tip burrowing, projection of vacuum and flow, and speed to roll the quadrants into the central space for aspiration.
The amount of nuclear material which can be removed is difficult to estimate, but a geometric calculation using a similar technique which leaves three remaining fragments demonstrated a $69 \%$ possible reduction in nucleus volume prior to fragment mobilization. ${ }^{5}$ The quadrant shaving technique described herein may allow even greater nuclear volume reduction.

Regardless of absolute size of the remaining plates, when they are mobilized centrally, they are thinner, more manageable, and less likely to bump up against the iris and corneal endothelium as they are removed. With the aspiration of each plate, the remaining ones are rotated to form a physical insulator, which protects the posterior capsule and helps contain the process by stabilizing the plate which was being emulsified. The last plate does not have the advantage of that insulation, and in order to stay away from the posterior capsule, is always removed in a more anterior location within the iris plane and anterior chamber. For this reason, the last plate to be removed should be a smaller one, and if it is hard, Viscoat reinjection should be considered.

Especially important with hard cataracts, Viscoat and its reinjection prior to removal of the last quadrant contributes greatly to the physical insulation of the corneal endothelium from nuclear fragment abrasion and acoustic energy transmission and absorption associated with the emulsification process. ${ }^{18,19}$ Corneal endothelial cell losses as low as $1.2 \%$ continue to be reported while using Viscoat during phacoemulsification. ${ }^{20}$ This dispersive viscoelastic is no doubt critical to the low cell losses reported in this paper. When it is not used, even with adjunctive femtosecond laser nucleus dissection and very little phacoemulsification energy, ECD losses have been shown to be as high as $12.1 \% .^{21,22}$

Although different, the ECD changes in this study were not statistically significantly different whether using torsional IP or longitudinal tip motion during quadrant removal. Reasons for this lack of difference could be small sample sizes, the fact that the losses were both so low that a significant difference was more difficult to identify, or that most of the phacoemulsification energy was expended in longitudinal mode during sculpting for both groups. The main point is that, given the study of hard cataracts, corneal endothelial 
cell losses were low with this technique regardless of tip motion in quadrant removal.

The machine-measured CDE may be higher with this technique vs phaco chop because of the time and energy required during sculpting and aspiration of nuclear emulsate during low-vacuum volume reduction. But the acoustic energy created by the vibrating tip during that process is essentially endocapsular and well away from the corneal endothelium, making the CDE less relevant to the prediction of corneal endothelial health after surgery. Using the debulking technique described here, added forgiveness is enjoyed during the more demanding high-vacuum aspiration phase of surgery because the remaining thin nuclear plates require less manipulation, less time to manipulate, and smaller amounts of ultrasonic energy to remove in a largely endocapsular process well away from the corneal endothelium.

\section{Disclosure}

Dr Davison is a paid consultant to Alcon, but has no financial or proprietary interest in any material or method mentioned in this manuscript.

\section{References}

1. Shepherd JR. In situ fracture. J Cataract Refract Surg. 1990;16:436-440.

2. Gimbel HV. Divide and conquer nucleofractis phacoemulsification: development and variations. J Cataract Refract Surg. 1991;17: 281-291.

3. Nagahara K. Phaco chop. Video presented at: The ASCRS/ASOA 3rd American International Congress on Cataract, IOL and Refractive Surgery; May 8-12; 1993; Seattle, WA.

4. Davison JA, Cionni RJ, Snowdon RJ, et al. Simultaneous surgeon and side-view video analysis comparing in situ fracture and stop-and-chop phacoemulsification. J Cataract Refract Surg. 2005;31:274-279.

5. Woodlief NF, Woodlief JM. Endocapsular deep-wedge-removal phacofracture. J Cataract Refract Surg. 2009;35:1656-1658.

6. Davison JA. Hybrid nuclear dissection technique for capsular bag phacoemulsification. J Cataract Refract Surg. 1990;16:441-450.

7. Arshinoff SA. Dispersive-cohesive viscoelastic soft shell technique. J Cataract Refract Surg. 1999;25:167-173.
8. Alcon Laboratories, Inc. Infiniti Vision System Operator's Manual. Fort Worth, TX: Alcon Laboratories, Inc; 2007.

9. Chylack LT Jr, Wolfe JK, Singer DM, et al. The Lens Opacities Classification System III: The Longitudinal Study of Cataract Study Group. Arch Ophthalmol. 1993;111:831-836.

10. Helvacioglu F, Yeter C, Tunc Z, Sencan S. Outcomes of torsional microcoaxial phacoemulsification performed by 12-degree and 22-degree bent tip. J Cataract Refract Surg. 2013;39:1219-1225.

11. Helvacioglu F, Sencan S, Yeter C, Tunc Z, Uyar O. Outcomes of torsional microcoaxial phacoemulsification using tips with 30-degree and 45-degree aperture angles. J Cataract Refract Surg. 2014;40:362-368.

12. Davison JA. Cumulative tip travel and implied followability of longitudinal and torsional phacoemulsification. J Cataract Refract Surg. 2008;34:986-990.

13. Reuschel A, Bogatsch H, Barth T, Wiedemann R. Comparison of endothelial changes and power settings between torsional and longitudinal phacoemulsification. J Cataract Refract Surg. 2010;36:1855-1861.

14. Davison JA, Chylack LT. Clinical application of the lens opacities classification system III in the performance of phacoemulsification. $J$ Cataract Refract Surg. 2003;29:138-145.

15. Bourne WR, Minassian DC, Dart JK, Rosen P, Kaushal S, Wingate N. Effect of cataract surgery on the corneal endothelium: modern phacoemulsification compared with extracapsular cataract surgery. Ophthalmology. 2004;111(4):679-685.

16. Liu Y, Zeng M, Liu X, et al. Torsional mode versus conventional ultrasound mode phacoemulsification: randomized comparative clinical study. J Cataract Refract Surg. 2007;33:287-292.

17. Park J, Yum HR, Kim MS, Harrison AR, Kim EC. Comparison of phaco-chop, divide-and-conquer, stop-and-chop phaco techniques in microincision coaxial cataract surgery. J Cataract Refract Surg. 2013; 39(10):1464-1469.

18. Petroll WM, Jafari M, Lane SS, Jester JV, Cavanagh HD. Quantitative assessment of ophthalmic viscosurgical device retention using in vivo confocal microscopy. J Cataract Refract Surg. 2005;31(12): 2363-2368.

19. Poyer JF, Chan KY, Arshinoff SA. New method to measure the retention of viscoelastic agents on a rabbit corneal endothelial cell line after irrigation and aspiration. J Cataract Refract Surg. 1998;24(1):84-90.

20. Moschos MM, Chatziralli IP, Sergentanis TN. Viscoat versus Visthesia during phacoemulsification cataract surgery: corneal and foveal changes. BMC Ophthalmol. 2011;11:9.

21. Conrad-Hengerer I, Hengerer FH, Schultz T, Dick HB. Effect of femtosecond laser fragmentation on effective phacoemulsification time in cataract surgery. J Refract Surg. 2012;28(12):879-883.

22. Conrad-Hengerer I, Al Juburi M, Schultz T, Hengerer FH, Dick HB. Corneal endothelial cell loss and corneal thickness in conventional compared with femtosecond laser-assisted cataract surgery: three-month follow-up. J Cataract Refract Surg. 2013;39(9):1307-1313.
Clinical Ophthalmology

\section{Publish your work in this journal}

Clinical Ophthalmology is an international, peer-reviewed journal covering all subspecialties within ophthalmology. Key topics include: Optometry; Visual science; Pharmacology and drug therapy in eye diseases; Basic Sciences; Primary and Secondary eye care; Patient Safety and Quality of Care Improvements. This journal is indexed on Submit your manuscript here: http://www.dovepress.com/clinical-ophthalmology-journal

\section{Dovepress}

PubMed Central and CAS, and is the official journal of The Society of Clinical Ophthalmology (SCO). The manuscript management system is completely online and includes a very quick and fair peer-review system, which is all easy to use. Visit http://www.dovepress.com/ testimonials.php to read real quotes from published authors. 